\title{
Monitoring of labor with WHO modified partogram - A study report
}

\author{
Md. Alauddin, Runa Bal, Arunangsu De, Parthajit Mondal, Mayoukh Chakraborty \\ Dept. of Gynecology and Obstetrics, Calcutta National Medical College \\ Institute of Post Graduate Medical Education and Research,
}

\begin{abstract}
Introduction: Partogram represents labor events. World Health Organisation (WHO) had produced a partogram in the last decade and subsequently modified it to make it easier to use. The present study was conducted to note the effectiveness of the WHO modified partogram.
\end{abstract}

Methods: Altogether 430 primigravida women, at term, having single live fetus in vertex presentation, were included for the study. The women were randomly subdivided into three groups: Group A (180 women) monitoring of labor done by WHO modified partogram; Group B (150 women)- monitoring of labor done by WHO original partogram and 100 women in Group C (control), the labor would be monitored clinically. The results were noted in each group regarding the length of labor, vaginal delivery, cesarean sections, augmentation of labor etc. The results of Group A were compared with Group B and Group C.

Result: The comparison of the results of the Group A and Group B did not reveal any statistically significant difference.

The comparison of the results of the Group A and Group C observed that significantly less number of women in Group A (4.44\%) was in labor for more than 12 hours than in Group C (18\%). The number of vaginal delivery was more and cesarean section was less in Group A than Group C ( $<<0.05)$. More number of women required augmentation of labor in Group C $(p<0.001)$.

Conclusion: WHO modified partogram, which is easier to use, gives almost the same effects as the WHO original partogram but significantly better results than clinical monitoring.

Key words: Labor monitoring, WHO modified partogram.

\section{Introduction}

Partogram is the Greek word meaning Labor curve. The proper visualization of the intra partum events can only be possible if we use the partogram perfectly. A partogram is able to indicate the optimum timing regarding any intervention during the labor procedure including transfer of the parturient to a referral center. Partogram is being used since Philpott and Castle introduced it in the year $1972 .{ }^{1}$ World Health Organisation (WHO) produced and promoted a partogram, which includes a latent phase of labor of eight hours, was tested in a multi centric trial involving 35,484 women in South East Asia. The result of the trial was published in $1994 .^{2}$ Subsequently, the WHO partogram had been modified to make it simpler and easier to use. The latent phase had been removed and plotting begins in the active phase when the cervix is 4 cm dilated.

The aim of the present study was to compare the different results obtained in primigravida by monitoring the labor procedures using the WHO modified partogram, WHO original partogram or without using any partogram (control) regarding the length of the labor, augmentation with oxytocin, delivery outcomes and occurrence of post partum complications.

Correspondence

Dr. Runa Bal

37, Talbagan Road, Kolkata- 700122, Phone number: (033) 25921355, 9830155463

Email-drruna70@yahoo.com 


\section{Method}

Altogether 430 primigravida women, aged 19 to 26 years, after completion of 37 weeks of gestation and not post term, having single live fetus in vertex presentation without any significant medical or obstetric complications, were chosen when they were admitted in the labor observation room of our hospital with spontaneous onset of labor pain. All the women were booked cases of our hospital and had routine antenatal investigations including ultrasonography. Patients were included in the study only after true labor is diagnosed and were randomly subdivided into three groups: Group A-comprises of 180 women in whom the labor process would be monitored by using WHO modified partogram; Group B- consisting of 150 women and their labor process would be monitored by using WHO original partogram; 100 women would be in Group C (control) - the labor process would be monitored clinically, without any partogram.

In Group A, partographic monitoring of labor with modified WHO partograph started in active phase of labor, i.e., when cervix was four $\mathrm{cm}$. or more dilated. Before that, i.e., in the latent phase, labor was monitored clinically. In Group B, labor monitoring started using WHO original partograph as soon as true labor started, i.e., in the latent phase. In Group C, the whole duration of labor was monitored clinically starting from the onset of true labor pain, without using partograph. Women, admitted with labor pain, with cervical dilatation $8 \mathrm{~cm}$ or more were not included in the study. In Group C, the interventions (oxytocin administration, instrumental delivery or cesarean section) were done according to the clinical assessment. In the other two groups, the partogram was used and interventions were done on the basis of partographic findings e.g., when the action lines were crossed.

The results were noted in each group regarding the total length of the labor (measured as the duration from the onset of true labor pain to completion of the third stage of labor), delivery outcomes e.g., spontaneous vaginal delivery, forceps delivery and cesarean section (CS), augmentation of labor with oxytocin, and the occurrence of post partum complications. The results obtained by using WHO modified partograph (Group A) were compared with those obtained by using WHO original partograph (Group B) and with the clinically monitored group (Group C). Statistical analysis was done by Chi square test and the significant differences were noted.

\section{Result}

The mean age of the women was 22.5 years in Group A, 23.1 years in Group B and 22.2 years in Group C.

Table 1 shows the comparison of the results of the Group A (monitoring of labor done by WHO modified partogram) and Group B (monitoring of labor done by WHO original partogram). In Group A, $4.44 \%$ women had the length of the labor lasting for more than 12 hours and in Group B, $4.66 \%$ of women had the same. Spontaneous vaginal delivery occurred in $82.7 \%$ of women in Group A and $80.66 \%$ of women in Group B. Regarding the number of women who had forceps delivery, our observation noted almost same incidence in both the groups. The cesarean section incidence was less in Group A. It was observed that $9.44 \%$ of women needed augmentation of labor with oxytocin in Group A while $10.66 \%$ of women in Group B needed it. One woman in Group A had puerperal sepsis. None of the parameters showed any statistically significant difference between the two groups.

Table 2 shows the comparison of the results of the Group A and Group C (control). It is observed that significantly less number of women in Group A (4.44\%) had the duration of the labor lasting for more than 12 hours than in Group C (18\%). There is significantly more number of vaginal delivery and less number of cesarean section in Group A when compared to Group $\mathrm{C}(\mathrm{p}<0.05)$ while the incidence of forceps delivery

Table I. Comparison of the outcomes of Group A and Group B

\begin{tabular}{lccc}
\hline Outcome & $\begin{array}{c}\text { Group A(n=180) } \\
\text { No. of women (\%) }\end{array}$ & $\begin{array}{c}\text { Group B(n=150) } \\
\text { No. of women (\%) }\end{array}$ & P value \\
\hline Length of labor> 12 hrs. & $8(4.44 \%)$ & $7(4.66 \%)$ & $>0.5$ \\
Spontaneous Vaginal delivery & $149(82.7 \%)$ & $121(80.66 \%)$ & $>0.5$ \\
Forceps delivery & $15(8.33 \%)$ & $14(9.33 \%)$ & $>0.5$ \\
Cesarean section & $16(8.88 \%)$ & $15(10 \%)$ & $>0.5$ \\
Labor augmented & $17(9.44 \%)$ & $16(10.66 \%)$ & $>0.5$ \\
Obstructed labor & 0 & 0 & $>0.5$ \\
Post partum hemorrhage & $7(3.88 \%)$ & $5(3.33 \%)$ & - \\
Puerperal sepsis & $1(0.55 \%)$ & 0 & - \\
\hline
\end{tabular}


Table 2. Comparison of the outcomes of Group A and Group C

\begin{tabular}{lccc}
\hline Outcome & $\begin{array}{c}\text { Group A(n=180) } \\
\text { No. of women (\%) }\end{array}$ & $\begin{array}{c}\text { Group B(n=100) } \\
\text { No. of women (\%) }\end{array}$ & P value \\
\hline Length of labor> 12 hrs. & $8(4.44 \%)$ & $18(18 \%)$ & $<0.001$ \\
Spontaneous Vaginal delivery & $149(82.7 \%)$ & $71(71 \%)$ & $<0.05$ \\
Forceps delivery & $15(8.33 \%)$ & $11(11 \%)$ & $>0.1$ \\
Cesarean section & $16(8.88 \%)$ & $18(18 \%)$ & $<0.05$ \\
Labor augmented & $17(9.44 \%)$ & $28(28 \%)$ & $<0.001$ \\
Obstructed labor & 0 & $2(2 \%)$ & - \\
Post partum hemorrhage & $7(3.88 \%)$ & $6(6 \%)$ & $>0.1$ \\
Puerperal sepsis & $1(0.55 \%)$ & $5(5 \%)$ & $<0.02$ \\
\hline
\end{tabular}

shows no significant difference $(\mathrm{p}>0.01)$. Indications of cesarean section in all groups included non-progress of labor, prolonged labor and fetal distress. The indications were almost equally divided in all three groups. Apart form these indications, two cases of Group C had cesarean section due to obstructed labor. Comparatively much more number of women required augmentation of labor with oxytocin in Group $\mathrm{C}$ than in Group A ( $\mathrm{p}<0.001)$. Only two women had obstructed labor in Group $\mathrm{C}$ while the incidence of post partum hemorrhage and puerperal sepsis showed no significant difference between the two groups.

Regarding the Apgar score (one minute) of the babies, there was no significant difference found between the three groups.

\section{Discussion}

The reports of monitoring of labor after introduction of WHO original partogram showed a reduction in prolonged labor by $41 \%$ and in emergency caesarean sections by $3 \%$ despite a reduction in the number of labors augmented by oxytocin by $54 \%$. A fall in the mean number of vaginal examinations during labor probably contributed to the $59 \%$ reduction in cases of postpartum sepsis. ${ }^{4}$ The report of WHO showed that $4.5 \%$ of women had prolongation of labor for $>18$ hours where WHO original partogram was used ${ }^{2}$ while our study showed $4.66 \%$ of women had the labor duration of $>12$ hours where WHO original partogram was used (Group B) and $4.44 \%$ of women had the same where WHO modified partogram was used (Group A). Without using any partogram (Group C), our study depicts that $18 \%$ of women had the duration of labor $>12$ hours while other study recorded $8.3 \%$ of women had labor duration for $>18$ hours $^{2}$. Without using any partogram, the cesarean section rate was $9.8 \%$ and it was $6.9 \%$ where labor was monitored with WHO original partogram ${ }^{2}$. We had $18 \%$ cesarean section rate in the control group (Group C) and $8.88 \%$ and $10 \%$ in Group A and Group B respectively. Lower incidence of cesarean section in Group A and B resulted from meticulous partographic monitoring of labor which avoided premature and unnecessary intervention in the form of CS for perceived abnormal progress of labor, where as, premature and unnecessary intervention for perceived non - progress or prolonged labor, specially in the latent phase, resulted in higher rate of CS in Group C. The incidence of vaginal delivery with the use of WHO original partogram was $78.3 \%{ }^{2}$ while we had $80.66 \%$ in Group B and $82.7 \%$ in Group A. The rate of augmentation of labor was $13.7 \%$ with WHO original partogram and $32.1 \%$ where no partogram was used ${ }^{2}$ where as we had the augmentation rate of $9.44 \%$ in Group A, $10.66 \%$ in Group B and 28\% in Group C. The post partum complications in our study were comparable to the previous study. ${ }^{2}$

\section{Conclusion}

The present study revealed significantly superior results of the outcomes of labor monitoring with the use of WHO modified partogram in comparison to the control group where no partogram was used. While comparing the outcomes between the two groups where the WHO modified partogram and WHO original partogram were used, no significant difference was observed. But, the WHO modified partogram is much easier and simpler to use and can even be used by non-specialist doctors and midwives or nurses. It also reduces the chance of premature and unnecessary intervention for perceived prolonged latent phase by excluding latent phase from the graph and starting plotting from $4 \mathrm{~cm}$. of cervical dilation. Thus, WHO modified partogram is simpler and easier to use while retaining all the efficacies of the original partogram and its benefits should be elaborately discussed with the doctors and midwives to ensure safe delivery practices. 


\section{References}

1. Philpott RH, Castle WM. Cervicographs in the management of labour in primigravidae. Journal of Obstetrics and Gynaecology of the British Commonwealth 1972;79:592-602.

2. World Health Organisation Maternal and Safe Motherhood Programme. World Health
Organisation partograph in management of labour. Lancet.1994;343:1399-1404.

3. Managing complications in pregnancy and child birth. A guide for midwives and doctors. Figure C10 The WHO Modified Partograph. www.who.int/reproductive-health/impac/ clinical_principles/figureC10.html

4. Lenox C. WHO partogram helps. BMJ 1994; 309:1016. 